\begin{tabular}{|c|c|c|c|c|}
\hline $\begin{array}{c}\text { 118SHARE: SOCIAL WORK } \\
\text { JURNAL }\end{array}$ & VOLUME: 7 & NOMOR: 1 & HALAMAN: $1-129$ & $\begin{array}{l}\text { ISSN:2339 -0042 }(p) \\
\text { ISSN: } 2528-1577 \\
(e)\end{array}$ \\
\hline
\end{tabular}

\title{
PENGANGGULANGAN KEMISKINAN MELALUI PENGEMBANGAN ASET KOMUNITAS
}

\author{
Oleh: \\ Muhammad Fedryansyah ${ }^{1} \&$ Risna Resnawaty $^{2}$ \\ 1. Pusat Studi Kewirausahaan Sosial, CSR dan Pengembangan Masyarakat FISIP-Universitas Padjadjaran \\ 2. Pusat Studi Kewirausahaan Sosial, CSR dan Pengembangan Masyarakat FISIP-Universitas Padjadjaran \\ (muhammad.fedryansyah@unpad.ac.id; risna.resnawaty@unpad.ac.id)
}

\begin{abstract}
ABSTRAK
Penanggulangan kemiskinan merupakan salah satu tujuan utama dalam pembangunan yang dilakukan di daerah. Terkait dengan hal tersebut, orientasi pembangunan yang bergeser dari top down menjadi bottom up juga menjadi dasar bagi pemerintah daerah dalam merancang berbagai program pembangunan. Begitupula yang dilakukan oleh pemerintah daerah Kabupaten Sumedang, yang berupaya untuk menanggulangi kemiskinan di wilayahnya. Dalam penelitian ini, akan difokuskan pada penanggulangan kemiskinan melalui pengembangan asset komunitas dengan mengambil kasus di wilayah Kecamatan Jatinangor, Kabupaten Sumedang. Pengembangan asset komunitas merupakan salah satu kajian dalam bidang ilmu kesejahteraan sosial, terutama dalam kajian pengembangan masyarakat. Metode yang digunakan dalam penelitian ini adalah kualitatif dengan melakukan analisis berdasarkan interpretasi dari data primer maupun sekunder. Proposisi dari penelitian ini adalah penanggulangan kemiskinan dapat dilakukan melalui pengembangan asset komunitas yang ada di masyarakat. Hasil dari penelitian ini menunjukkan bahwa dari dari lima tipe asset komunitas (fisik, sumberdaya manusia, sosial, lingkungan, dan finansial) yang ada di Kecamatan Jatinangor, asset yang dapat dikembangkan adalah asset fisik, asset sumber daya manusia, dan asset sosial. Dengan demikian, pemerintah daerah Kabupaten Sumedang dapat merancang program pembangunan dengan memanfaatkan asset yang sudah ada tersebut (fisik, sumber daya manusia, dan sosial).

Kata kunci : kemiskinan, pengembangan masyarakat, asset komunitas.
\end{abstract}

\begin{abstract}
Poverty is one of the problems faced by local governments. The transformation of development paradigm from top down to bottom up, became guideline for local government to design their programs. And also the government in Sumedang Regency, that had designed various programs to faced poverty problems. This research will be focused on poverty alleviation through the development of community's assets in Jatinangor District. Community's assets is one of the studies in the field of social welfare science, especially in the study of community development. The method used in this research is qualitative by doing analysis based on interpretation from primary and secondary data. The proposition of this research is that poverty problem can be solved through the development of community's assets. The results of this study indicate that from the five types of assets (physical, human resource, social, environmental, and financial) in Jatinangor, the potential assets are physical assets, human resources assets and social assets. Therefore, the local government could directed programs that optimization those assets (physical assets, human resource assets, and social assets).

Key words : poverty, community development, community's assets.
\end{abstract}




\section{Pendahuluan}

Dalam beberapa periode terakhir, paradigma pembangunan mulai bergeser dari top down menjadi bottom up. Argumen yang muncul dari pergeseran tersebut adalah keyakinan bahwa pembangunan yang bersifat top down hanya menimbukan keseragaman dalam pembangunan, mengesampingkan perbedaan karakteristik, budaya serta kebutuhan yang ada di setiap daerah. Halligan dan Aulich (dalam Hoessein, 2004:4) juga menyebutkan bahwa kebijakan ini (pendekatan top down) telah menimbulkan dampak berupa pengabaian terhadap nilai-nilai demokrasi dan kemajemukan masyarakat.

Pembangunan pada hakikatnya bertujuan untuk meningkatkan kesejahteraan masyara-kat. Namun, masih banyak program-program pembangunan yang ternyata tidak berdampak pada peningkatan kesejahteraan masyarakat. Kemiskinan, sebagai salah satu indikator yang mengukur tingkat kesejahteraan masyarakat, masih menjadi masalah yang dihadapi dalam pelaksanaan programprogram pembangunan. Kartasasmita (1996: 234) juga menyebutkan bahwa kemiskinan merupakan masalah dalam pembangunan yang kemudian meningkat menjadi ketimpangan.

Permasalahan ini juga dihadapi oleh pemerintah daerah Kabupaten Sumedang. Secara umum, persentase kemiskinan dan pengangguran di Kabupaten Sumedang masih di atas rata-rata tingkat provinsi dan pusat. Dari persentase tingkat kemiskinan dan pengangguran di provinsi dan pusat rata-rata 8 persen, di Kabupaten Sumedang mencapai 12 persen.

Terkait dengan kondisi tersebut, dapat dilihat pada kondisi di salah satu kecamatan di Kabupaten Sumedang, yaitu Kecamatan Jatinangor. Dimana, kondisi kemiskinan terjadi sebagai akibat dari perubahan dalam struktur pekerjaan. Terutama terjadinya pergeseran dari sektor pertanian ke sektor industri dan jasa. Namun, lapangan kerja tersebut tidak diserap oleh penduduk Jatinangor melainkan penduduk pendatang. Hal ini disebabkan secara geografis Kecamatan Jatinangor berbatasan dengan kabupaten lain, sehingga tenaga kerja dari luar kabupaten banyak yang bekerja di wilayah ini.

Hasil sensus tenaga kerja yang meliputi 12 desa di Jatinangor, menunjukkan bahwa lebih dari $21 \%$ penduduk di Jatinangor adalah penganggur atau bekerja dengan pola dan penghasilan yang tidak jelas.

Untuk menanggulangi masalah kemiskinan tersebut, pemerintah daerah Kabupaten Sumedang juga telah mengeluarkan Peraturan Bupati
Sumedang Nomor 34 Tahun 2009 tentang Pembentukan Tim Koordinasi Penanggulangan Kemiskinan Kabupaten Sumedang. Kebijakan tersebut diarahkan untuk membangun sinergitas pelaksanaan penanggulangan kemiskinan di Kabupaten Sumedang.

Secara teoritis, penanggulangan kemiskinan dapat dilakukan dengan memanfaatkan potensi yang ada di masyarakat. Potensi yang ada di masyarakat dapat didefinisikan sebagai asset yang ada di masyarakat. Menurut Green and Haines (2002 : 8), dalam pengembangan masyarakat dapat dipandang sebagai usaha yang terencana untuk membangun aset yang meningkatkan kapasitas penghuni untuk memperbaiki kualitas hidup mereka. Setidaknya terdapat lima tipe aset yang ada di komunitas yaitu asset fisik, asset manusia, asset sosial, asset finansial, dan asset lingkungan. Pengembangan asset komunitas tersebut dapat menjadi salah satu solusi dalam upaya penanggulangan masalah kemiskinan di Jatinangor.

Peneilitian ini mencoba untuk mendeskripsikan bentuk-bentuk dari asset komunitas yang ada di Jatinangor sebagai bagian dalam upaya penanggulangan kemiskinan di Jatinangor.

\section{Metode Penelitian}

Penelitian ini bermaksud untuk mengkaji asset komunitas yang dapat dikembangkan dalam upaya penanggulangan kemiskinan di Kecamatan Jatinangor. Untuk mendapatkan gambaran mengenai bentuk-bentuk dari asset tersebut, maka dalam penelitian ini digunakan metode deskriptif dan pendekatan kualitatif.

Pengumpulan data dalam kegiatan ini terdiri dari data sekunder dan data primer. Data sekunder diarahkan kepada dokumen-dokumen terkait dengan kebijakan dan program penanggulangan kemiskinan yang ada di Kabupaten Sumedang. Sedangkan data primer diarahkan untuk menggali informasi secara langsung di lapangan terkait dengan asset komunitas, yang dilakukan dengan cara menggunakan wawancara mendalam serta melakukan Focus Group Discussion. Penelitian ini melibatkan 30 orang informan yang dipandang memiliki pengetahuan dan informasi mengenai kondisi di desa-desa yang ada di Kecamatan Jatinangor. Informan tersebut terdiri dari aparat pemerintahan desa, tokoh masyarakat, serta masyarakat awam yang ada di setiap desa. 


\section{Asset Komunitas di Kecamatan Jatinangor}

Asset komunitas merupakan asset yang ada dan dimiliki oleh masyarakat di setiap desa yang ada di Kecamatan Jatinangor. Dari hasil penelitian lapangan diketahui bahwa setiap desa memiliki aset masing-masing, dengan ciri khas dan daya tarik dari tiap-tiap desa. Untuk mendapatkan gambaran mengenai bentuk-bentuk asset komunitas yang ada di tiap desa, pada bagian berikut akan dideskripsikan bentuk-bentuk asset komunitas yang ada di Kecamatan Jatinangor. Adapun kelima asset tersebut antara lain : asset fisik, asset sumberdaya manusia, asset sosial, asset finansial, dan asset lingkungan.

Asset fisik merupakan asset dasar meliputi infrastruktur-infrastruktur yang ada di setiap desa untuk digunakan dalam membantu masyarakat mencapai kehidupan yang lebih baik. Berdasarkan hasil penelitian lapangan diketahui asset fisik yang dimiliki setiap desa berbeda sesuai dengan pembangunan dan kebutuhannya. Asset fisik tersebut berupa infrastruktur atau sarana yang ada di masyarakat antara lain : sarana pendidikan, sarana kesehatan, pasar/mall, keagamaan, olahraga, perumahan, perhotelan, serta pabrik.

Dari sarana tersebut yang ada di masyarakat tersebut, sarana pendidikan menjadi sarana yang paling banyak dan ada di setiap desa. Status Kecamatan Jatinangor yang dikenal sebagai wilayah pendidikan memiliki infrastruktur pendidikan dari jenjang pendidikan dasar sampai pendidikan tinggi. Infrastruktur lain (kesehatan, pasar/mall, keagamaan, olahraga, perumahan, perhotelan, dan pabrik), ada di masyarakat namun tidak merata di setiap desa.

Asset finansial merupakan asset dasar yang ada dan dimiliki masyarakat yang dapat dimanfaatkan masyarakat Jatinangor untuk mencapai kesejahteraan. Berdasarkan hasil penelitian lapangan diketahui bahwa asset finansial yang ada di masyarakat Jatinangor dibagi kedalam dua kelompok, kelompok pertama merupakan asset finansial yang muncul dari dalam masyarakat dan yang kedua adalah asset finansial yang berasal dari luar masyarakat. Asset finansial yang muncul dari dalam masyarakat yaitu kegiatan-kegiatan ekonomi yang dibentuk berdasarkan kebutuhan, keinginan dan adanya partisipasi masyarakat. Sebagai gambaran, asset ekonomi tersebut seperti koperasi, BUMdes, lumbung pangan serta kelompok arisan. Asset finansial yang berasal dari luar masyarakat antara lain lembaga ekonomi yang beroperasi dari masyarakat. Perkembangan pesat di wilayah Jatinangor juga memancing pertumbuhan ekonomi di wilayah tersebut. Pertumbuhan ekonomi yang pesat tersebut dikarenakan adanya perguruan tinggi dan pabrikpabrik yang mengundang pendatang untuk beraktivitas di Jatinangor. Berbagai bank nasional telah ada saat ini seperti Bank Rakyat Indonesia (BRI), Bank Bukopin, Bank Nasional Indonesia (BNI), Bank Mandiri, Bank Tabungan Negara (BTN), Bank CIMB, Bank BJB, Bank Perkreditan Rakyat BPR berada di Desa Cibeusi, serta Bank Pembangunan Daerah Jabar di Desa Hegarmanah.

Asset lingkungan merupakan asset yang berdasarkan kepada sumberdaya alam yang ada di setiap desa. Dari hasil temuan diketahui bahwa karakteristik dari asset lingkungan berbeda-beda di setiap desa. Kondisi tersebut dipengaruhi oleh letak geografis masing-masing desa. Sumberdaya alam yang ada di Kecamatan Jatinangor saat ini ditentukan oleh pembangunan yang ada di setiap desa. Satu-satunya hasil sumberdaya alam yang ada di Jatinangor adalah sumberdaya di sektor pertanian. Hal tersebut dikarenakan lahan-lahan pertanian dan perkebunan yang ada di Jatinangor saat ini sudah mulai berkurang.

Asset berikutnya yang ada di masyarakat Jatinangor adalah asset sosial. Sebagai sebuah kesatuan, masyarakat memiliki nilai dan norma yang mengatur hubungan satu sama lainnya. Nilai dan norma tersebut dibentuk sebagai upaya mempertahankan eksistensi dari suatu kelompok masyarakat agar bisa bertahan ditengah modernisasi dan akulturasi budaya yang semakin hari semakin menekan budaya asli dari suatu masyarakat. Dalam konteks penelitian ini, nilai dan norma termasuk kedalam aset sosial yang dimiliki oleh masyarakat. Masyarakat Jatinangor mayoritas merupakan suku sunda yang menerapkan nilai, bahasa dan budaya didalam kehidupan sehari-hari. Salah satu nilai sunda yang masih diterapkan yaitu "Sabilulungan" yang berarti seiya, sekata, seayun selangkah, sepengertian sepemahaman, senasib sepenanggungan, saling mendukung, saling menyayangi, dan saling membantu. Dengan demikian kegiatan yang ada di masyarakat haruslah mengendapankan kegotong royongan. Kegiatan lainnya yang ada di masyarakat adalah pengajian rutin yang dilakukan di setiap desa, aktifitas kepemudaan melalui organisasi karang taruna, serta organisasi PKK. Selanjutnya, aset sosial juga dilihat dari lembaga-lembaga kesenian lokal. Beberapa jenis kesenian yang setiap desa miliki adalah reak, kuda renggong, marawis, dan qasidahan. Selanjutnya adalah kelompok karang taruna. 
Asset terakhir adalah sumber daya manusia, yang dapat dilihat dalam beberapa hal seperti jumlah penduduk, perkembangan penduduk, tingkat pendidikan, mata pencaharian penduduk. Tingkat potensi sumber daya manusia yang ada di Kecamatan Jatinangor berdasarkan jenis kelamin bahwa potensi sumber daya manusia sangat besar. Hampir di setiap desa jumlah laki-laki lebih banyak dibandingkan dengan perempuan kecuali di Desa Cilayung. Potensi sumberdaya manusia tersebut juga dapat dilihat dari usia masyarakat Jatinangor. Dari data sekunder yang didapatkan maka dapat dilihat bahwa potensi sumber daya manusia sangat besar, karena jumlah penduduk didominasi oleh penduduk pada usia produktif yaitu pada usia 16 sampai 45 tahun sebanyak 6.447 orang atau $43 \%$ dari jumlah penduduk. Potensi sumber daya manusia yang ada di Kecamatan Jatinangor menurut tingkat pendidikan menunjukan bahwa tingkat pendidikan masih rendah karena tingkat pendidikan penduduk sebagian besar tamat SMP yaitu sebanyak 2.554 orang.

\section{Pengembangan Asset Fisik, Asset Sumber Daya Manusia, dan Asset Sosial Di Kecamatan Jatinangor}

Pengembangan asset komunitas dapat dilakukan dengan melihat ketersediaan asset tiap desa di Kecamatan Jatinangor. Dari hasil penelitian lapangan, dapat diketahui bahwa semua desa yang ada di Kecamatan Jatinangor memiliki asset fisik.

Aset fisik merupakan aset dasar meliputi infrastruktur-infrastruktur yang ada di setiap desa untuk digunakan dalam membantu masyarakat mencapai kehidupan yang lebih baik. Berdasarkan hasil penelitian lapangan diketahui aset fisik yang dimiliki setiap desa berbeda sesuai dengan pembangunan dan kebutuhannya. Bentuk-bentuk asset fisik yang ada antara lain sarana pendidikan, sarana kesehatan, sarana ibadah, sarana olahraga, pasar, perhotelan, apartemen, mall, serta kawasan pabrik. Berikut penjabaran dari asset fisik tersebut.

Sarana pendidikan, Kecamatan Jatinangor terkenal sebagai wilayah pendidikan karena terdapat berbagai Infrastruktur dari berbagai jenjang pendidikan meliputi Paud, TK, SD, SMP, SMA/SMK dan Universitas. Tidak setiap desa memiliki infrastrutktur pendidikan tersebut namun disesuaikan dengan kebutuhan dan letak geografis desa tersebut berada.

Sarana kesehatan, kesejahteraan masyarakat salah satunya ditentukan oleh tingkat kesehatan masyarakat. Pemerintah dalam hal ini Dinas Kesehatan berupaya untuk meningkatkan kesehatan masyarakat melalui penyediaan infrastruktur kesehatan yang telah didirikan yaitu Puskesmas sebanyak 1 unit, Puskesmas Pembantu 3 unit, Posyandu sebanyak 127 unit. Infrastruktur kesehatan tersebut tersebar di setiap desa di Kecamatan untuk mempermudah masyarakat dalam pengobatan kesehatan.

Sarana ibadah, masyarakat Jatinangor saat ini masih tergolong sebagai masyarakat agamis. Kegiatan-kegiatan keagamaan masih banyak dilakukan di setiap desanya. Mayoritas pemeluk agama di Kecamatan Jatinangor adalah Islam, sisanya beragama Katolik, Protesta, Budha, dan Hindu. Untuk memenuhi kebutuhan spiritual warga masyaraka Jatinangor, masyarakat desa melalui swadaya dan pemerintah membangun masjid dan mushola yang tersebar di setiap desa di Kecamatan Jatinangor. Sedangkan masyarakat yang beragama selain Islam, di dalam kampus IPDN terdapat gereja katolik dan Gereja Protesta, serta vihara untuk digunakan sebagai tempat beribadah. Selain di IPDN, terdapat pula gereja di Desa Hegarmanah yang diperuntukan bagi jamaah pemeluk agama kristen Protestan.

Sarana olahraga, kegiatan berolahraga merupakan kegemaran dari masyarakat Jatinangor. Setiap minggu pagi banyak warga yang melakukan aktivitas berolhraga di sekitar kampus Universitas Padjadjaran dan ITB. Kegiatan olahraga tersebut juga rutin dilakukan di sekitaran desa tempat warga bertempat tinggal.

Pasar, untuk menunjang perekonomian masyarakat Jatinangor hanya terdapat satu pasar tradisional yang berada di Desa Cibeusi. Pasar tersebut yang menyediakan kebutuhan premier dan sekunder seperti sayur mayur, daging, ikan, beras, perlengakapn rumah tangga sampai perlengkapan sekolah anak.

Perhotelan, kegiatan ekonomi di Kecamatan Jatinangor lambat laun semakin pesat seperti halnya di kota-kota besar. Kegiatan ekonomi tersebut mengundang para pendatang untuk melakukan aktivitas di sekitaran Wilayah Kecamatan Jatinangor, akibatnya adalah kebutuhan akan hotel semakin mendesak. Untuk memenuhi kebutuhan tersebut, maka dibangunlah beberapa hotel yang berdiri wilayah Kecamatan Jatinangor. Saat ini hotel yang telah didirikan di Kecamatan Jatinangor berjumlah 8 hotel tersebar di beberapa desa.

Apartemen, pembangunan di wilayah Kecamatan Jatinangor saat ini salah satunya berpusat kepada pembangunan hunian atau tempat tinggal. Sampai saat ini setidaknya ada 11 apartemen yang sudah mengantongi ijin operasional, 4 diantaranya sudah berdiri sejak tahun 2010. Pembangunan 
apartemen tersebut tersebar di beberapa desa di Kecamatan Jatinangor.

Mall, perkembangan Kecamatan Jatinangor menuju wilayah perkotoan dibutikan dengan hadirnya mall di kawasan tersebut. Jatinangor Town Square atau yang lebih dikenal dengan nama JATOS adalah salah satu pusat perbelanjaan/mall yang dibangun di atas area seluas $30.000 \mathrm{~m}^{2}$ yang terdiri dari 4 lantai dengan luas bangunan \pm $24.000 \mathrm{~m}^{2}$ yang berada di lokasi sangat strategis.

Kawasan pabrik, selain dikenal sebagai kawasan pendidikan, wilayah lainnya dari Kecamatan Jatinangor adalah Kawasan industri. Sejak tahun 1980 kawasan Jatinangor mulai didirikan pabrikpabrik berskala nasional. Pabrik yang pertama kali muncul adalah parik tekstil, antara lain Five Star, Kewalraf, sedangkan Pabrik Kahatex terhitung sebagai pabrik paling besar yang terletak di desa Cintamulya. Kawasan pabrik yang saat ini beroperasi berada di Desa Cisempur, Desa Cintamulya yaitu pabrik Kahatex, pabrik Yogi Saputra, Supratek dan Banon, di Desa Mekargalih yaitu Pabrik Insan Sindang dan Desa Cipacing yaitu Pabrik Wiska dan Polypin Canggih.

Selain asset fisik, asset lain yang secara umum terdapat di desa-desa di Kecamatan Jatinangor adalah asset sumber daya manusia. Pontesi sumberdaya tersebut dapat dilihat dalam beberapa hal seperti jumlah penduduk, perkembangan penduduk, tingkat pendidikan, mata pencaharian penduduk.

Tingkat potensi sumber daya manusia yang ada di Kecamatan Jatinangor berdasarkan jenis kelamin bahwa potensi sumber daya manusia sangat besar, jumlah laki-laki lebih besar daripada perempuan. Dimana, penduduk laki-laki berjumlah 53.509 jiwa dan penduduk perempuan berjumlah 51.362 jiwa. Hampir di setiap desa jumlah laki-laki lebih banyak dibandingkan dengan perempuan kecuali di Desa Cilayung.

Potensi sumberdaya manusia tersebut juga dapat dilihat dari usia masyarakat Jatinangor. Dari data sekunder yang didapatkan maka dapat dilihat bahwa potensi sumber daya manusia sangat besar, karena jumlah penduduk di dominasi oleh penduduk pada usia produktif yaitu pada usia 16 sampai 45 tahun.

Usia produktif memegang peran penting dalam pembangunan di Kecamatan Jatinangor. Disamping dengan banyaknya usia produkti, tingkat pendidikan masyarakat Jatinangor juga bisa dijadikan sebagai potensi sumberdaya manusia. Tingkat potensi sumber daya manusia yang ada di Kecamatan Jatinangor menurut tingkat pendidikan menunjukan bahwa tingkat pendidikan rendah karena tingkat pendidikan penduduk sebagian besar tamat SMP.

Asset yang ketiga, yang secara umum dimiliki oleh masyarakat Jatinangor adalah asset sosial. Nilai dan norma termasuk kedalam aset sosial yang dimiliki oleh masyarakat. Masyarakat Jatinangor mayoritas merupakan suku sunda yang menerapkan nilai, bahasa dan budaya didalam kehidupan sehari-hari. Dimana, nilai gotong royong masih berjalan dalam kehidupan sosial masyarakat. Beberapa desa masih memegang teguh nilai tersebut seperti di Desa Cileles, Desa Cilayung, Desa Jatimukti yang secara demografi masih belum terlalu banyak pendatang yang tinggal dan menetap disana. Hadirnya pendatang memiliki pengaruh dalam perubahan nilai-nilai yang ada dalam masyarakat. Kegiatan gotongroyong yang masih berlangsung di setiap desa adalah kegiatan ronda, membersihkan kampung, perayaan hari kemerdekaan, perayaan kegamaan.

Kegiatan lainnya yang ada di masyarakat adalah pengajian rutin yang dilakukan di setiap desa. Walaupun berbeda-beda hari pelaksanaannya, pengajian merupakan kegiatan rutin yang dilakukan oleh masyarakat. pengajian untuk orang dewasa biasanya dilakukan pada malam hari, sedangkan untuk anak-anak dilakukan di surau pada sore hari. Kegiatan pengajian ini dimaksudkan untuk memperdalam ilmu kegamaan serta ajang silaturahmi dari setiap masyarakat untuk mengetahui keadaan satu sama lainnya masing-masing.

\section{Penutup}

Dari hasil penelitian diketahui bahwa asset komunitas yang dapat dikembangkan dalam penanggulangan kemiskinan di Jatinangor antara lain adalah asset fisik, asset sumber daya manusia, dan asset sosial. Adapun bentuk asset fisik yang dapat dikembangkan adalah pemanfaataan sarana pendidikan dan kesehatan yang ada di setiap desa di Jatinangor. Dimana, masyarakat didorong untuk mendapatkan layanan pendidikan yang lebih baik serta promosi kesehatan masyarakat dapat lebih digalakkan.

Terkait dengan pemanfaatan asset sumber daya manusia dan asset sosial, program penanggulangan kemiskinan dapat dilakukan dengan peningkatan kapasitas penduduk. Peningkatan kapasitas dapat dilakukan dalam bentuk penyediaan pelatihan-pelatihan teknik bagi penduduk laki-laki yang sesuai dengan kebutuhan pasar tenaga kerja di Jatinangor. Sedangkan, untuk asset sosial, program-program penanggulangan kemiskinan dapat dikembangkan 


\begin{tabular}{|c|c|c|c|c|}
\hline $\begin{array}{c}\text { 118SHARE: SOCIAL WORK } \\
\text { JURNAL }\end{array}$ & VOLUME: 7 & NOMOR: 1 & HALAMAN: $1-129$ & $\begin{array}{l}\text { ISSN:2339 -0042 }(p) \\
\text { ISSN: } 2528-1577 \\
(e)\end{array}$ \\
\hline
\end{tabular}

dengan mengedepankan nilai-nilai gotong royong di masyarakat.

Adapun saran yang dapat direkomendasikan antara lain pelibatan para stakeholder dalam pengembangan asset komunitas di Jatinangor. Mengingat tanggungjawab penanggulangan kemiskinan tidak hanya dibebankan kepada pemerintah saja, melainkan terdapat pula peran dari pihak swasta dan masyarakat.

\section{Daftar Pustaka}

Chambers, Robert. 1987. "Rural Development Putting the Last First". New York : Jhon Wiley dan Son.

Colby, Ira. 2008. "Comprehensive Handbook of Social Work and Social Welfare". Volume 4. Canada: John Wiley\&Sons, Inc.

Hall, Anthony \& James Midgley. 2004. "Social Policy for Development". London: Sage Publications.

Hilgartner, S. \& Bosk, C.L. 1988. "The Rise and fall of social problems: A Public arena model". The American Journal of Sociology, 94 (1), 53-78.

Hoessein, Bhenyamin. 2004. "Hubungan Penyelenggaraan Pemerintah Pusat dengan
Pemerintah Daerah". Jakarta : Jurnal Bisnis dan Birokrasi No. 1/vol 1 Juli.

Kartasasmita, Ginanjar. 1993. "Kemiskinan". Jakarta : Balai Pustaka

Korten, David C. 2001. "Menuju Abad ke-21 : Tindakan Sukarela dan Agenda Global". Jakarta : Yayasan Obor Indonesia

Mardimin, Johanes (edd). 1996. "Dimensi Krisis Proses Pembangunan di Indonesia". Yogyakarta : Penerbit Khusus

Rubin, Allen and Earl R. Babbie. 2008. "Research Methods for Social Work". Belmont: Thomson Brooks/Cole.

Soetrisno, Loekman. 2001. "Menuju Masyarakat Partisipatif". Yogyakarta : Kanisius.

Sumodiningrat, Gunawan. 1999. "Kemiskinan : Teori, Fakta dan Kebijakan". Jakarta : Penerbit IMPAC

Supriatna, Tjahya. 2000. "Strategi Pembangunan dan Kemiskinan". Bandung : Humaniora Utama Press

Suwandi, Made. 2000. "Struktur Pemerintah Daerah". Jakarta

Thompson, Neil. 2005. "Understanding Social Work". London : Palgrave. 